\title{
Paralemmin-1 is expressed in lymphatic endothelial cells and modulates cell migration, cell maturation and tumor lymphangiogenesis
}

\author{
Imke Albrecht $\cdot$ Raphael Bieri $\cdot$ Angela Leu • \\ Philipp Granacher · Jörg Hagmann • \\ Manfred W. Kilimann · Gerhard Christofori
}

Received: 19 January 2013/Accepted: 19 May 2013/Published online: 26 May 2013

(C) Springer Science+Business Media Dordrecht 2013

\begin{abstract}
The lymphatic system, the network of lymphatic vessels and lymphoid organs, maintains the body fluid balance and ensures the immunological surveillance of the body. In the adult organism, the de novo formation of lymphatic vessels is mainly observed in pathological conditions. In contrast to the molecular mechanisms governing the generation of the lymphatic vasculature during embryogenesis, the processes underlying pathological lymphangiogenesis are less well understood. A genomewide screen comparing the transcriptome of tumor-derived lymphatic endothelial cells with that of blood vessel endothelial cells identified paralemmin-1 as a protein
\end{abstract}

Electronic supplementary material The online version of this article (doi:10.1007/s10456-013-9356-7) contains supplementary material, which is available to authorized users.

I. Albrecht · R. Bieri - A. Leu - P. Granacher · J. Hagmann ·

G. Christofori $(\bowtie)$

Department of Biomedicine, University of Basel, Mattenstrasse

28, 4058 Basel, Switzerland

e-mail: gerhard.christofori@unibas.ch

Present Address:

I. Albrecht

Drug Discovery Biology, Actelion Pharmaceutical Ltd,

Allschwil, Switzerland

Present Address:

R. Bieri

Swiss Tropical and Public Health Institute, Basel, Switzerland

M. W. Kilimann

Department of Otolaryngology, University of Göttingen Medical

Center, Göttingen, Germany

M. W. Kilimann

Department of Molecular Neurobiology, Max-Planck-Institute

for Experimental Medicine, Hermann-Rein-Str. 3, 37075

Göttingen, Germany prominently expressed in lymphatic endothelial cells. Paralemmin-1 is a lipid-anchored membrane protein that in fibroblasts and neurons plays a role in the regulation of cell shape, plasma membrane dynamics and cell motility. Here, we show that paralemmin-1 is expressed in tumor-derived lymphatic endothelial cells as well as in lymphatic endothelial cells of normal, non-tumorigenic tissue. Paralemmin-1 represses cell migration and delays the formation of tube-like structures of lymphatic endothelial cells in vitro by modulating cell-substrate adhesion, filopodia formation and plasma membrane blebbing. While constitutive genetic ablation of paralemmin-1 expression in mice has no effect on the development and physiological function of the lymphatic system, the loss of paralemmin-1 impaired tumor-associated lymphangiogenesis. Together, these results newly identify paralemmin-1 as a protein highly expressed in lymphatic endothelial cells. Similar to its function in neurons, it may link the cytoskeleton to the plasma membrane and thereby modulate lymphatic endothelial cell adhesion, migration and lymphangiogenesis.

Keywords Angiogenesis - Cancer - Cell migration · Lymphangiogenesis $\cdot$ Paralemmin

\section{Introduction}

After its formation during embryonic and postnatal development, the lymphatic vasculature is mostly quiescent. Lymphatic vessels only grow in a few physiological situations such as pregnancy. In contrast, a number of disease conditions are accompanied by the de novo formation of lymphatic vessels. Pathological lymphangiogenesis, as it is called, has been shown to occur in wound healing, tissue repair, inflammation, organ transplant rejection and cancer. 
In cancer, the formation of new lymphatic vessels (lymphangiogenesis) has received major attention, as it contributes to disease progression: in cancer patients, increased levels of lymphangiogenic growth factors and aberrantly activated lymphangiogenesis and higher lymphatic vessel densities are associated with lymph node metastasis and poor prognosis [1-3].

The molecular mechanisms of pathological lymphangiogenesis are not completely understood. Key players, which are essential for lymphatic development during embryogenesis include the forkhead transcription factor FoxC2 and the homeodomain transcription factor Prox-1, yet a variety of factors has been identified to modulate physiological and pathological lymphangiogenesis [4]. In the case of cancer, inflammatory cells, bone-marrow-derived progenitor cells and tumor cells promote lymphangiogenesis by secreting various lymphangiogenic growth factors, chemokines and cytokines. These factors, which include VEGF-C, VEGF-D, VEGF-A, PDGF-BB, FGF, HGF, IL- $1 \beta$, TNF $\alpha$ and others, stimulate lymphatic endothelial cell migration, proliferation and maturation and thus lymphatic vessel growth [5-7]. While the formation of lymphatic vessels is mainly based on the proliferation and migration of lymphatic endothelial cells from pre-existing lymphatic vessels, the incorporation of bone marrow-derived progenitor cells into growing lymphatic vessels has also been reported [8-10].

In order to identify new players involved in pathological lymphangiogenesis, we have performed a genome-wide transcriptional profiling of lymphatic endothelial cells (LEC) versus blood vessel endothelial cells (BEC) from normal tissue and from tumors with activated lymphangiogenesis. One of the genes preferentially expressed in LEC is paralemmin-1 (Palm1). Paralemmin-1, the founding member of the paralemmin gene family, is a $42 \mathrm{kDa}$ phosphoprotein anchored in the plasma membrane by its $\mathrm{C}$-terminal lipid tail [11]. Human and mouse, paralemmin-1 mRNA is differentially spliced to generate a full-length and an exon 8-deleted isoform [12]. Paralemmin-1 has been first identified in neurons where it is involved in the regulation of spine and synapse formation, presumably by the modulation of filopodia formation. Neurons depleted of paralemmin-1 develop significantly less filopodia and spines, whereas neurons overexpressing paralemmin-1 exhibit more [13]. Increased filopodia and process formation and cellular expansion have been also detected upon paralemmin-1 overexpression in non-neuronal cells [12]. Process formation depends on plasma membrane localization. It has therefore been suggested that the role of paralemmin- 1 consists in anchoring the cortical cytoskeleton to the plasma membrane [13, 14].

Here, we have investigated the functional role of paralemmin-1 in lymphangiogenesis by gain and loss of function experiments in cultured LEC in vitro and in mouse models in vivo. We find that paralemmin-1-depleted LEC exhibit altered adhesion and spreading behavior, which leads to increased LEC migration and accelerated formation of cord-like structures. In constitutive knockout mice, the loss of paralemmin-1 does not disturb the formation of the lymphatic vasculature during embryonic and postnatal development, perhaps due to homeostatic compensation. However, in a mouse model of tumor lymphangiogenesis, the absence of paralemmin- 1 results in reduced lymphatic vessel densities, indicating that paralemmin-1 plays a critical role in tumor lymphangiogenesis.

\section{Results}

Paralemmin-1 is expressed in lymphatic endothelial cells

To identify genes that were specifically expressed by lymphatic endothelial cells (LEC) during pathological lymphangiogenesis in a tumor setting, we isolated LEC and blood vessel endothelial cells (BEC) from pancreatic $\beta$-cell tumors of RIP1Tag2; RIP1VEGF-C double-transgenic mice and from islets of Langerhans from single-transgenic RIP1VEGF-C mice. RIP1Tag2 transgenic mice express the simian virus (SV) 40 large $\mathrm{T}$-antigen (Tag) under the control of the rat-insulin promoter (RIP) in the $\beta$-cells of the pancreatic islets of Langerhans and develop pancreatic insulinomas [15]. Transgenic RIP1VEGF-C mice express the lymphangiogenic factor VEGF-C in pancreatic $\beta$-cells and exhibit increased peri-insular lymphangiogenesis and lymphatic vessel density in the periphery of islets of Langerhans [16]. The simultaneous expression of SV40 Tag and VEGF-C in pancreatic $\beta$-cells in double-transgenic RIP1Tag2; RIP1VEGF-C mice results in the formation of peritumoral lymphatic vessels (Supplementary Figure 1A) promoting the occurrence of lymph node metastasis [16].

LEC and BEC were isolated from tumors of 12-weekold RIP1Tag2; RIP1VEGF-C and from islets of RIP1VEGF-C mice by flow cytometry sorting of $\mathrm{CD} 31^{+}$Podoplanin ${ }^{+}$Lyve- $1^{+}$LEC and CD $31^{+}$Podoplanin ${ }^{-}$Lyve- $1^{-}$ BEC from single cell suspensions (Supplementary Figure 1B). Total RNA was prepared from these cells and further processed for the subsequent hybridization to DNA microarrays. The transcriptional profile of LEC isolated from islets of RIP1VEGF-C and from tumors of RIP1Tag2; RIP1VEGF-C mice were, as expected, different from islets and tumors of BEC isolated from the same genotype animals (Supplementary Figure 1C). Transcript levels of known LEC and BEC markers were found to be up-regulated in the corresponding transcriptomes (Supplementary Figure 1D), indicating the successful separation of these two cell populations by flow cytometry. Comparing the transcriptome of tumor-derived LEC to that of islet-derived 
LEC, around 500 genes were found differentially expressed (twofold up or down in expression levels). Among the genes highly expressed in tumor LEC were genes associated with cell adhesion, remodeling of the extracellular matrix, immune response and cell proliferation (Supplementary Table I). Furthermore, the comparison of the transcriptome of LEC with that from BEC allowed the identification of genes specifically up-regulated in LEC.

One of the genes specifically expressed in LEC and not in BEC encoded for paralemmin-1 (Palm1), a neuronal gene thus far not reported expressed by LEC. Quantitative RT-PCR revealed that its mRNA levels were 13-fold higher in LEC as compared to BEC. To confirm the microarray and RT-PCR results, the expression of paralemmin-1 was analyzed by immunofluorescence microscopy. Cryosections of pancreata from RIP1VEGF-C and RIP1Tag2; RIP1VEGF-C mice were co-stained for paralemmin-1 and for common LEC markers, such as Lyve-1, Podoplanin and Prox-1. Paralemmin-1 co-localized with all three LEC markers, indicating that tumor-derived and isletassociated LEC expressed paralemmin-1 (Fig. 1). Next, cryosections of skin, diaphragm, heart, pancreas, intestine and tail obtained from normal C57B1/6 mice were stained for paralemmin-1 and Lyve-1 to assess whether paralemmin-1 was also expressed by the lymphatic vasculature of normal tissue and organs. In all tissues and organs, Lyve-1positive LEC also stained positive for paralemmin-1 (Fig. 2a). To distinguish blood vessels from lymphatic vessels, C57B1/6 mice were perfused with FITC-lectin prior to sacrifice, and tissue and organs were stained for paralemmin-1. In contrast to the lymphatic vasculature, FITC-lectin-labeled blood vessels did not co-localize with paralemmin-1 expression (Fig. 2b). Together, these results show that paralemmin-1 is specifically expressed both in activated as well as in quiescent LEC of the lymphatic vasculature but not in BEC of the blood vasculature.

\section{Paralemmin-1 modulates LEC adhesion and migration}

To assess the function of paralemmin-1 in LEC, paralemmin-1 expression was down-regulated in the two murine lymphatic endothelial cell lines SV-LEC and MELC using RNA interference [17, 18]. SV-LEC as well as MELC expressed the two known isoforms of paralemmin-1 as determined by immunoblotting and quantitative RT-PCR analysis (Supplementary Figures 2A, B, 3A). In SV-LEC, $48 \mathrm{~h}$ after transfection with two different siRNAs against paralemmin-1 [siPalm (1) and (2)], mRNA and protein levels of both paralemmin-1 isoforms were reduced by $75 \%$ compared to SV-LEC transfected with a control siRNA (siCont; Supplementary Figure 2A). In MELC, stably transfected with shRNAs targeting paralemmin-1 [shPalm (1) and (2)], mRNA and protein levels of

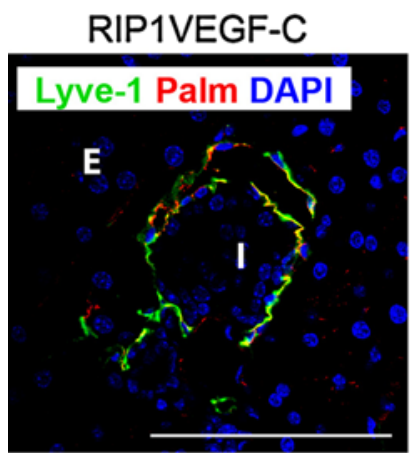

RIP1Tag2;RIP1VEGF-C
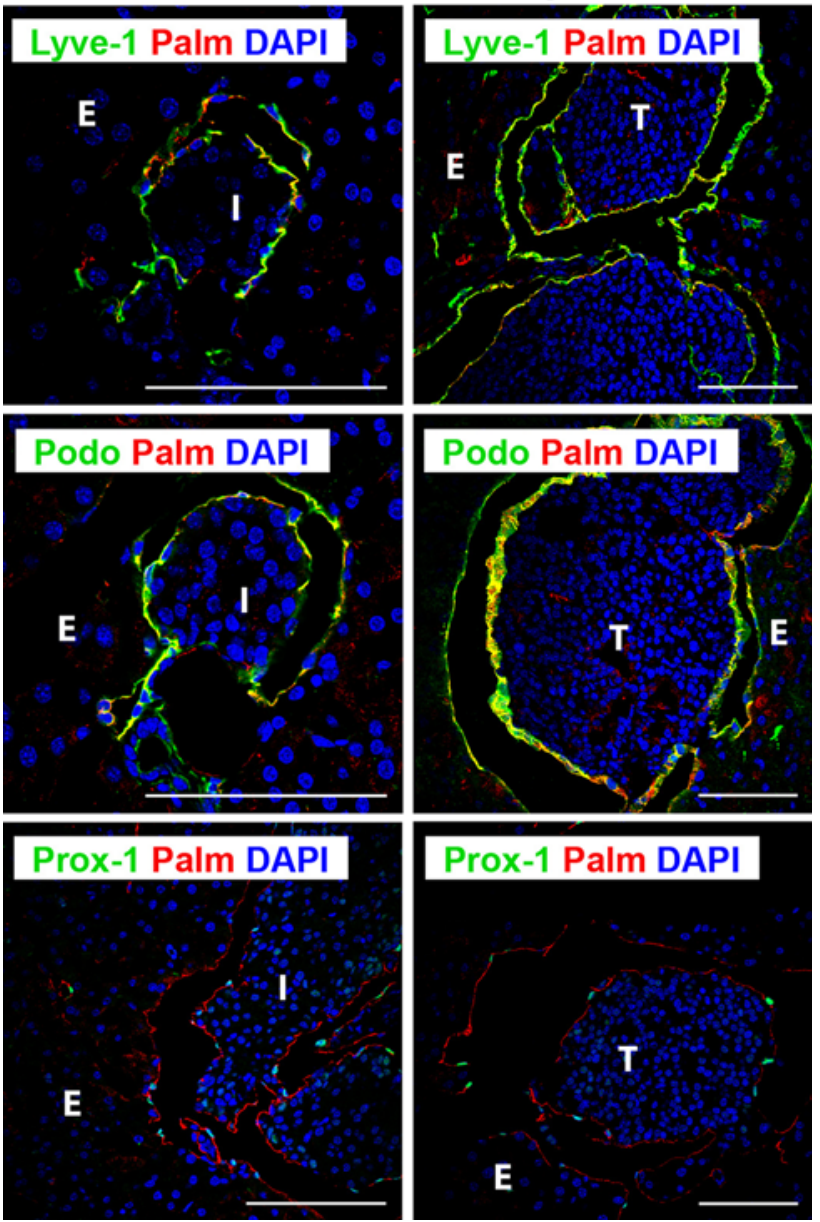

Fig. 1 Paralemmin-1 is expressed in activated and tumor-derived lymphatic endothelial cells. Representative immunofluorescence microscopy pictures of pancreatic sections from RIP1VEGF-C (left) and RIP1Tag2; RIP1VEGF-C (right) mice stained for paralemmin-1 (red) and for the lymphatic endothelial cell markers Lyve-1 (upper row), podoplanin (middle row) and Prox-1 (lower row). Nuclei were visualized by DAPI staining. Scale bars $100 \mu \mathrm{m} . \quad \mathrm{I}=$ islet, $\mathrm{T}=$ tumor, $\mathrm{E}=$ exocrine pancreas

paralemmin-1 could be reduced to around $50 \%$ (Supplementary Figure 2B). In contrast to SV-LEC, in MELC the two isoforms were not equally reduced. Besides paralemmin-1, SV-LEC and MELC express high levels of paralemmin-2 and, to a lesser extent, paralemmin-3 and 4 (Supplementary Figure 3A). Ablation of paralemmin-1 expression did not affect the expression of the other paralemmin family members (Supplementary Figure 3B).

In a Boyden chamber assay, SVLEC and MELC with reduced paralemmin-1 levels migrated significantly faster than control cells (Fig. 3a, b). Increased migration velocity may account for the accelerated formation of cord-like structures in Matrigel (Fig. 3c, d). Sixty minutes after seeding on Matrigel, the majority of paralemmin-1-depleted cells were attached to each other and started to form 


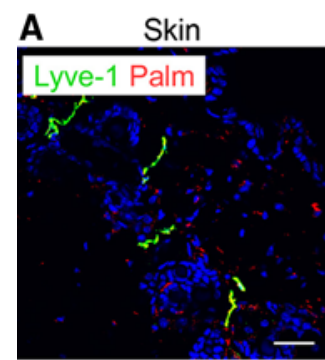

Pancreas
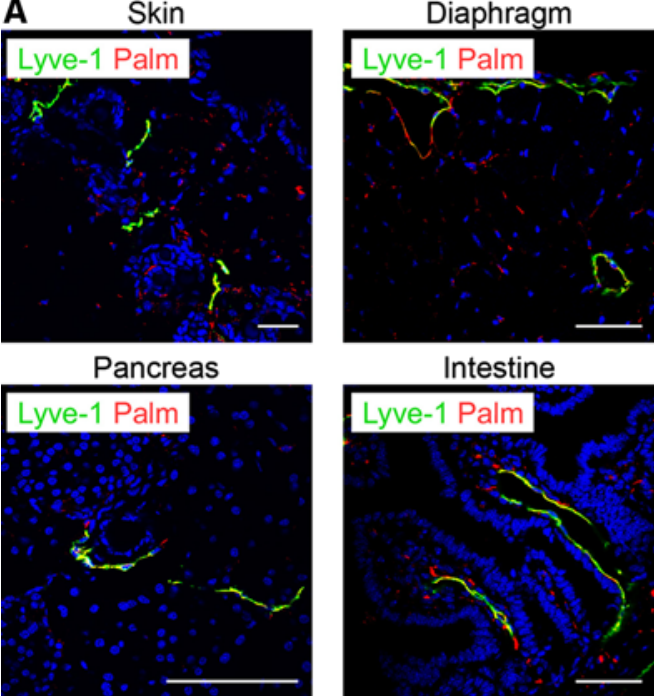

Intestine

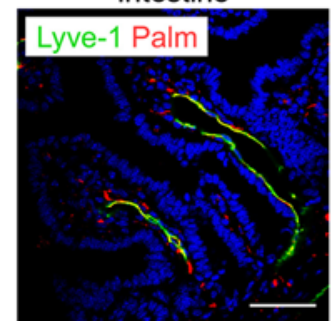

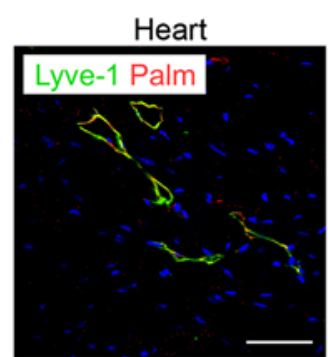

Tail

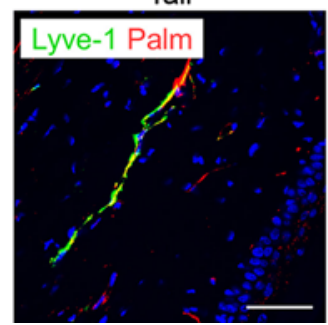

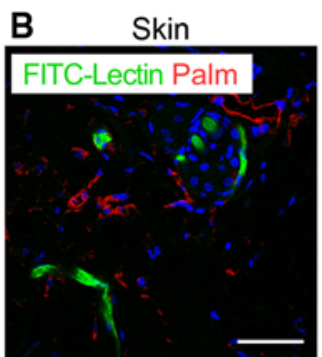

Pancreas

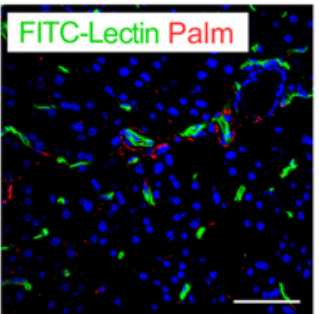

Diaphragm

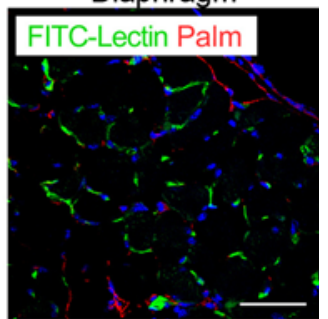

Intestine

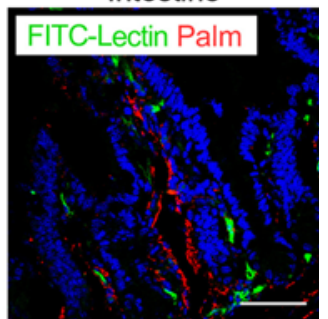

Fig. 2 Paralemmin-1 is expressed in lymphatic endothelial cells and not in blood vessel endothelial cells. a Representative immunofluorescence microscopy pictures of histological sections from six tissues of C57B1/6 mice stained for the LEC marker Lyve-1 (green) and paralemmin-1 (red). Nuclei were visualized with DAPI.

cord-like structures, whereas approximately $90 \%$ of the control cells were still found as single cells at this time point. An hour later, also the majority of the control cells were incorporated into cord-like structures.

Since changes in adhesion strength can directly influence cell migration [19-21], we next assessed whether the depletion of paralemmin expression alters LEC adhesion and spreading on solid substrates using live cell interference reflection microscopy (IRM). With IRM, the spreading and adhesion of cells on the glass surface of the slide can be quantified and followed over time. After adhesion and spreading on a glass coverslip, control siRNA-transfected (siCont) SV-LEC switched between cell expansion and retraction, while the average total adhesion area remained constant (Fig. 4a). The initial adhesion and spreading phase of knockdown (siPalm) and control cells was comparable. However, after spreading, 56-78\% of the paralemmin-1-deficient cells "contracted" and decreased their adhesion areas, a behavior found in only $4 \%$ of the control SV-LEC (Fig. 4b). Moreover, all "contracted" paralemmin-1-depleted cells exhibited a high and dynamic membrane blebbing activity, which was almost completely absent in control SV-LEC. Finally, paralemmin-1-depleted cells formed less filopodia as compared to control cells (Fig. 4c, upper panels).

The adhesion and spreading behavior of control and transient paralemmin-1 knockdown SV-LEC was also examined under more physiological conditions by plating the cells on cover slips coated with parallel $12 \mu \mathrm{m}$-wide fibronectin lines. The zones between the lines were coated b Immunofluorescence staining for paralemmin-1 (red) of sections of four tissues isolated from C57B1/6 mice perfused with the FITClectin to visualize functional blood vessels. Nuclei were counterstained with DAPI. Scale bars $100 \mu \mathrm{m}$

with PLL-PEG as an anti-adhesive substance. This 1D substrate forces cells into an uni-axial morphology and rapid unidirectional movement similar to what is observed in 3D matrices consisting of collagen fibers [22]. On fibronectin-coated lines, both control and paralemmin-1 knockdown cells assumed a uni-axial morphology with lamellipodia at the migrating front (Fig. 4c, lower panels). However, only paralemmin-1 knockdown SV-LEC showed membrane blebbing along their sides, whereas in control SV-LEC the plasma membranes formed straight lines with strong parallel cortical actin fibers. The appearance of plasma membrane blebs in paralemmin-1 knockdown cells could be the result of a destabilization of the interaction between the plasma membrane and the cytoskeleton. Indeed, immunofluorescence staining for actin and paxillin revealed that the cell protrusions of paralemmin-1-depleted cells possessed less stress fibers and focal adhesion sites (Supplementary Figure 4).

Taken together, these results show that paralemmin-1 exerts a critical role in substrate adhesion and motility of LEC, conceivably by modulating the interaction between the plasma membrane and the actin cytoskeleton.

Loss of paralemmin-1 affects pathological lymphangiogenesis

To determine the role of paralemmin-1 in LEC in vivo, we first analyzed constitutive paralemmin-1 knockout $\left(\mathrm{Palm}^{-1-}\right)$ mice. Palm ${ }^{-1-}$ mice appeared healthy, fertile and showed no overt phenotype. Importantly the mice did not display any 
Fig. 3 Knockdown of paralemmin- 1 expression in cultured lymphatic endothelial cells leads to increased cell migration, and to the accelerated formation of cordlike structures upon threedimensional culture in Matrigel. a Cell migration of SV-LEC and control (siCont) cells ablated for paralemmin- 1 expression by transient transfection with siRNAs against paralemmin-1 [siPalm (1) and (2)] determined in a Boyden chamber assay. ** $p<0.01 ; * * * p<0.001$ (Student's $t$ test). b Cell migration of MELC and control (shCont) cells ablated for paralemmin- 1 expression by the stable expression of shRNAs against paralemmin-1 [shPalm (1) and (2)] determined in a Boyden chamber assay. ** $p<0.01$ (Student's $t$ test). c, d Light microscopy images (left) and quantification (right) of the formation of cord-like structures upon threedimensional culture in Matrigel. SV-LEC were transiently depleted of paralemmin-1 (upper panel) and MELC were stably depleted of paralemmin-1 expression (lower panel) as described in (a) and (b). One representative experiment is shown. Scale bars $100 \mu \mathrm{m}$
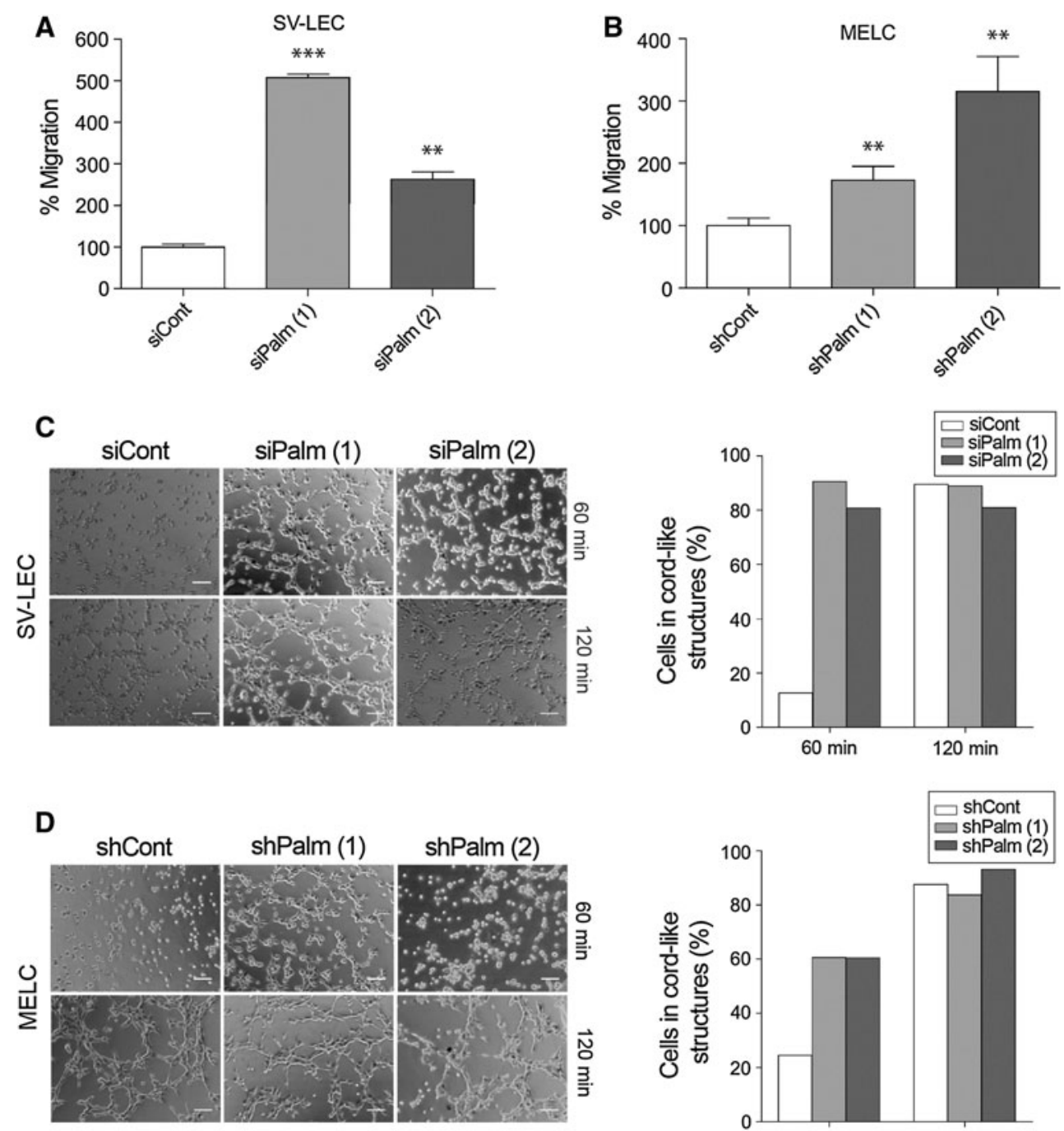

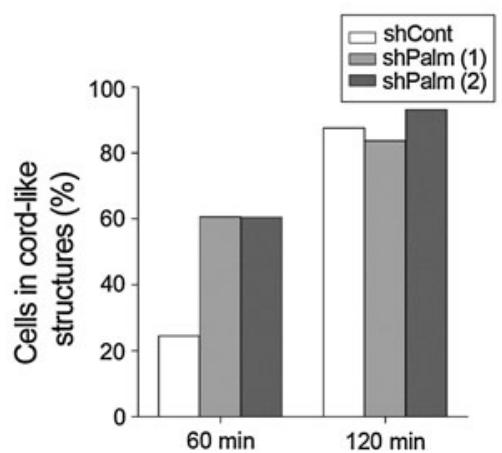

sign of lymphedema indicating that their lymphatic system was functional. Histological sections of various organs stained for Lyve-1 and CD31 demonstrated a normal lymphatic network and lymphatic vessel structure in Palm $^{-1-}$ mice (Fig. 5a). Whole-mount staining for Lyve-1 of the ear and diaphragm confirmed that the number and the structure of the lymphatic vessels in Palm ${ }^{-/-}$mice were comparable to those in C57Bl/6 control mice (Fig. 5b). The Lyve-1-positive lymphatic vessels of wildtype and knockout animals had similar diameter and length and they displayed a comparable degree of complexity (Fig. 5b).

Next, we examined whether the lymphatic vessels in paralemmin- $1^{-/-}$mice were functional in draining watersoluble dyes from the peripheral tissue. First, Chicago Blue was injected into the hind footpad of control C57Bl/6 and $\mathrm{Palm}^{-/-}$mice, and its drainage to the popliteal lymph nodes was monitored. Indeed, some minutes after injection, in both control and Palm ${ }^{-1-}$ mice the popliteal lymph node was stained blue (Fig. 6a). Second, low-molecular weight
FITC-Dextran was injected into the tip of the tail, and uptake and transport of FITC-Dextran was followed under a fluorescent stereomicroscope. The transport of FITCDextran by the tail lymphatic vasculature occurred with similar speed and efficiency in both control $\mathrm{Palm}^{+/+}$and Palm $^{-/-}$mice (Fig. 6b). These data indicate that paralemmin-1 is not required for the structure and physiological function of the lymphatic vasculature in adult mice.

Based on the observation that the lack of $\mathrm{Palm}^{-1-}$ in LEC led to accelerated cell migration and formation of cord-like structures, there could be a quantitative difference during the embryonic and postnatal development of the lymphatic vasculature. Hence, we investigated the development of the lymphatic network in the tail and the intestine of normal control mice and paralemmin-1 ${ }^{-/-}$ mice, which occurs after birth and follows distinct steps. In the tail, the formation of the superficial dermal lymphatic network starts with the generation of an irregular and discontinuous network of vessels which develop within 6 days 
Fig. 4 Knockdown of paralemmin-1 expression in cultured lymphatic endothelial cells affects cell adhesion, spreading, blebbing and filopodia formation. a SV-LEC were transiently transfected with control siRNA (siCont) or siRNAs against paralemmin-1 [siPalm (1) and siPalm (2)], and cell spreading on poly-L-lysine substratum was quantified by live cell reflection interference contrast microscopy (RICM). b Contraction of SV-LEC after cell spreading on poly-L-lysine substratum was quantified by differential interference contrast microscopy (DICM).

c Representative DICM images of control and paralemmin-1 knockdown SV-LEC taken during cell spreading on poly-Llysine (upper panels) and after plating on glass slides coated with single $10 \mu \mathrm{m}$ fibronectin lines next to anti-adhesive coating (lower panels). Scale bars $10 \mu \mathrm{m}$
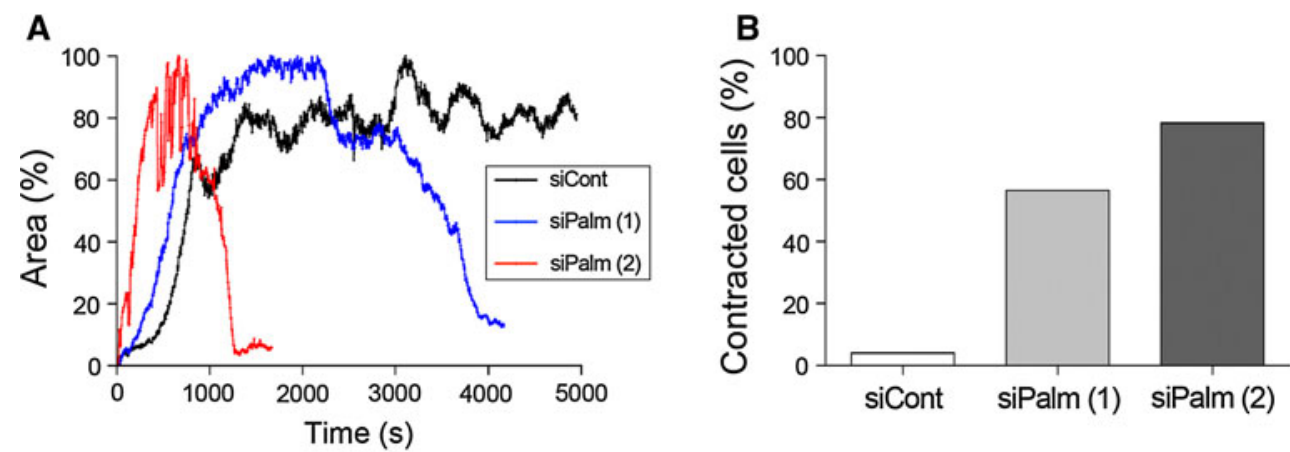

C
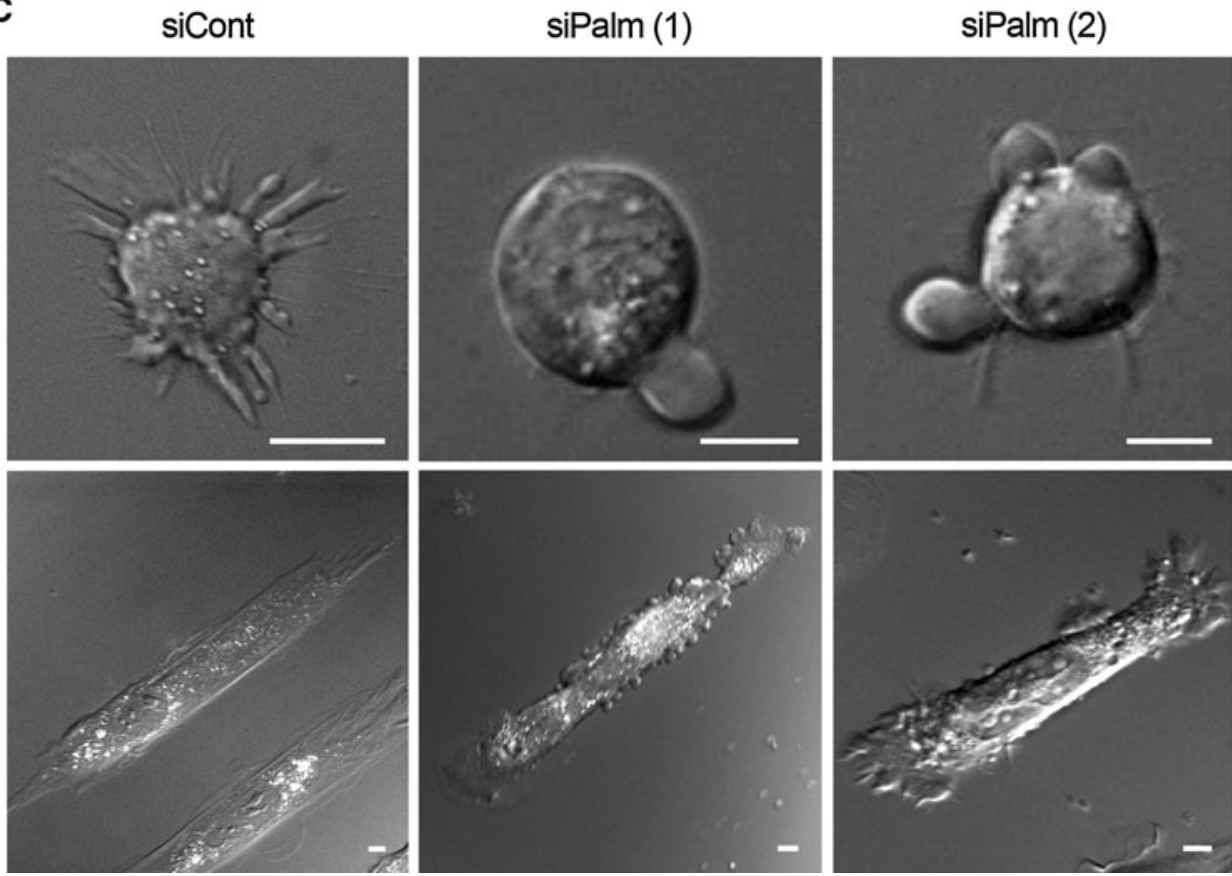

into the highly organized hexagonal lattice [23]. Tails and intestine of newborns at day P0, P2 and P8 were stained in whole mount for Lyve-1 (Fig. 6c). Comparing Palm ${ }^{+/+}$ and Palm ${ }^{-/-}$mice, the formation of the lymphatic network in the tail and of the intestinal villi, the so-called lacteals, was not affected by the lack of paralemmin-1.

Next we assessed whether paralemmin-1 was required for lymphangiogenesis in the adult organism. To this end, $\mathrm{Palm}^{-1-}$ mice were crossed with RIP1VEGF-C mice and RIP1Tag2; RIP1VEGF-C mice to generate RIP1VEGF-C; $\mathrm{Palm}^{-1-}$ and RIP1Tag2; RIP1VEGF-C; $\mathrm{Palm}^{-1-}$ mice. Pancreatic sections from these mice were then stained for Lyve-1 and CD31 and the stained area were quantified for blood microvessels density and lymphatic coverage of islets of Langerhans and of pancreatic insulinomas, respectively. The lymphatic coverage of the islet of Langerhans as well as the blood microvessel density in islets were comparable between RIP1VEGF-C; Palm $^{+/+}$and RIP1VEGF-C; Palm $^{-/-}$mice (Supplementary Figure 5). In the RIP1Tag2; RIP1VEGF-C; Palm ${ }^{-/-}$mice, the loss of paralemmin-1 did not change the number of pancreatic tumors nor did it influence tumor volumes or intra-tumoral blood microvessel densities as compared to RIP1Tag2; RIP1VEGF-C; Palm $^{+/+}$ mice (Fig. 7a, Supplementary Figure 6). However, the lymphatic coverage of the tumors was significantly reduced in RIP1Tag2; RIP1VEGF-C; Palm $^{-1-}$ mice compared to RIP1Tag2; RIP1VEGF-C; Palm $^{+/+}$mice (Fig. 7b, c). These data indicate that, while paralemmin-1 may not be required for physiological lymphangiogenesis, it is required for tumor lymphangiogenesis.

\section{Discussion}

We have identified paralemmin-1 to be prominently expressed by LEC of the lymphatic vasculature of various tissue types and organs. This paralemmin-1 staining, abolished in $\mathrm{Palm}^{-1-}$ mice, co-localized with the staining for the widely used LEC markers Prox-1, Lyve-1 and Podoplanin, indicating that paralemmin- 1 can serve as a new 

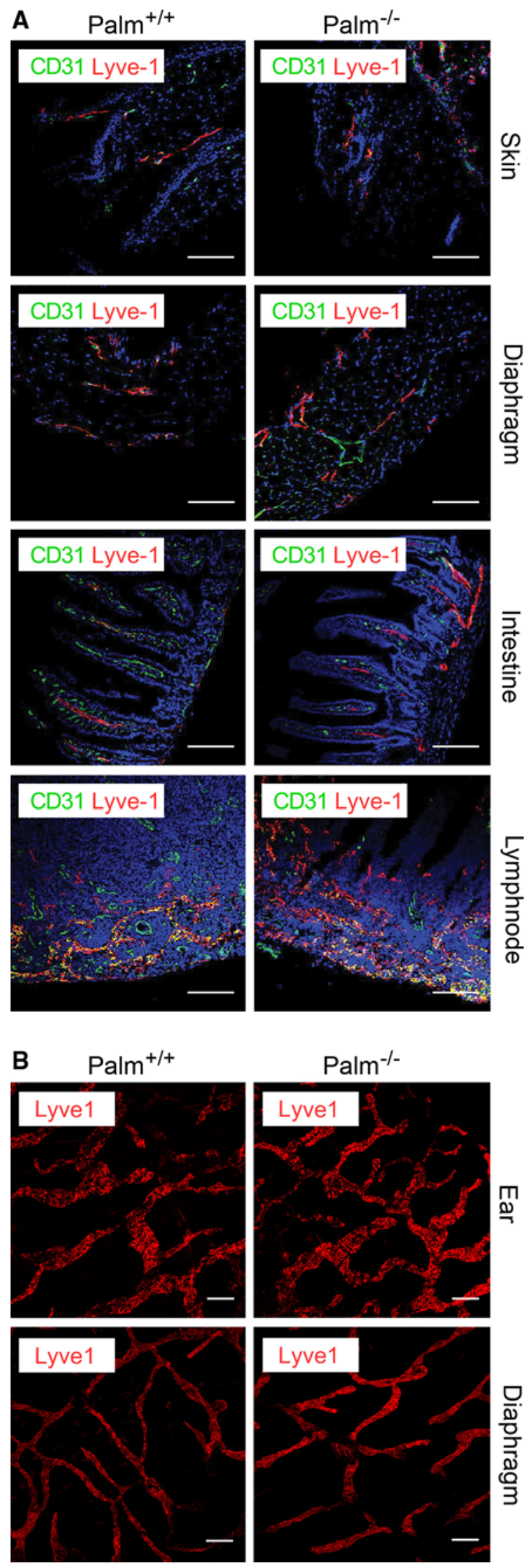

4 Fig. 5 Constitutive paralemmin-1 knockout mice $\left(\mathrm{Palm}^{-/-}\right)$have normal lymphatic system morphology. a Representative immunofluorescence staining of histological sections of various tissue from C57B1/6 $\left(\mathrm{Palm}^{+/+} ;\right.$left $)$and Palm ${ }^{-/-}$(right) mice stained for CD31 (BEC marker, green) and Lyve-1 (LEC marker, red). Nuclei were visualized with DAPI. Scale bars $100 \mu \mathrm{m}$. b Whole mount staining for Lyve- 1 of the ear and diaphragm from Palm ${ }^{+/+}$and Palm ${ }^{-/-}$mice to visualize the lymphatic system in these organs. Scale bars $100 \mu \mathrm{m}$

marker of LEC. In contrast, paralemmin-1 expression was not detected in BEC of various tissues investigated, indicating that blood endothelia do not express paralemmin-1 or at least at much lower levels than lymphatic endothelia. Previously, paralemmin-1 has been described by immunoperoxidase staining in subpopulations of blood endothelia of rat kidney and adrenal gland, though not brain [24], and of human mammary gland and breast cancers [25]. More comprehensive investigations will be needed to clarify in which types of blood vessels, under which physiological conditions, at which relative levels and by which techniques paralemmin-1 can be detected in BEC.

In LEC, paralemmin-1 may be involved in the regulation of the interaction between the plasma membrane and the actin cytoskeleton, as previously suggested for neurons and fibroblasts [12]. Ablation of paralemmin-1 expression in LEC leads to increased migration velocity and to an accelerated formation of cord-like structures upon 3D culture in Matrigel. Increased migration speed of paralemmin-1-deficient cells appears to be caused by a reduction in cell-substrate adhesion and an altered spreading behavior. This observation is consistent with previous reports demonstrating that lowering adhesion strength correlates with an increased cell speed, and vice versa [20, 21]. On surfaces with low adhesive properties, including glass slides, paralemmin-1-deficient LEC fail to properly adhere and to form filopodia, they rather contract and start to form plasma membrane blebs. The increased plasma membrane blebbing itself may also further contribute to the increase in migration speed by adapting to a more amoeboid form of cell migration [26], as can be seen with paralemmin-1-deficient cells that exhibit reduced focal adhesion sites and stress fibers.

The molecular mechanisms by which paralemmin-1 modulates these processes are not known. Adhesion of cells to the extracellular matrix (ECM) is initiated by binding of integrins to components of the ECM. We speculate that paralemmin-1 plays a critical role in the modulation of the recruitment of signaling molecules and actin-binding proteins to clustered integrins which finally leads to a reorganization of the actin cytoskeleton and the formation of filopodia and lamellipodia [27]. Our analysis has shown that paralemmin- 1 is not required for the initial binding of LEC cells to surfaces. However, cell spreading, 
A

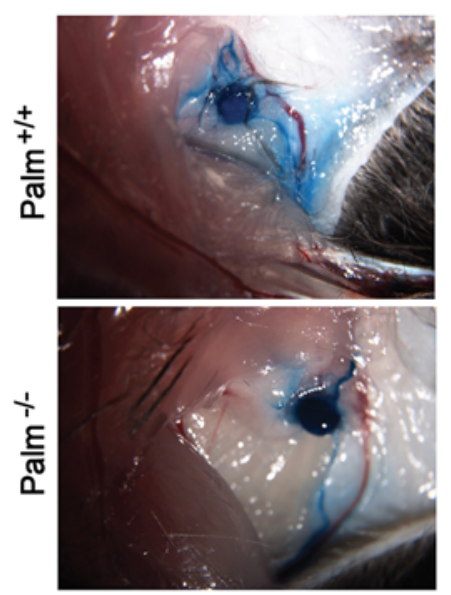

C

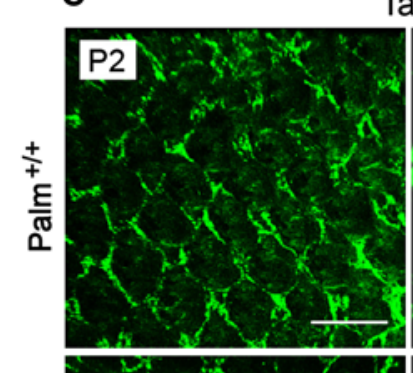

Tail
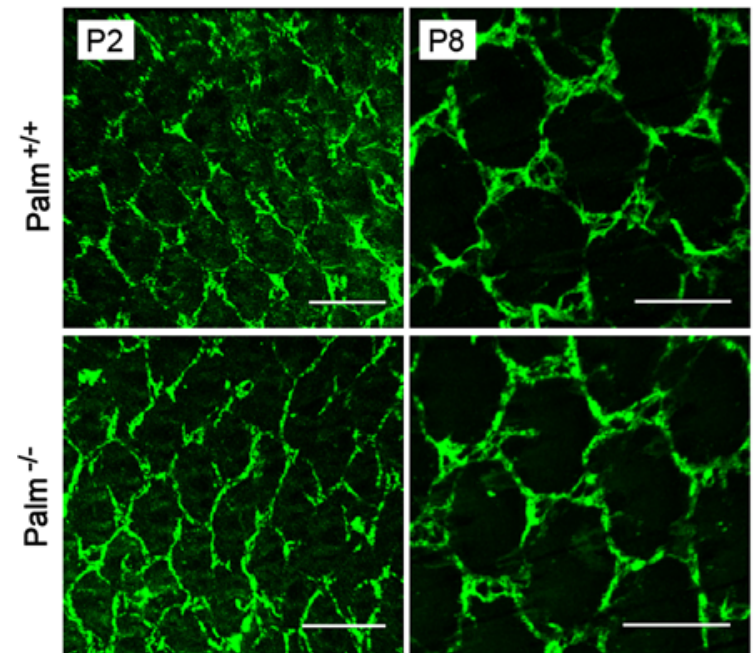

Fig. 6 The lymphatic system in paralemmin-1 knockout mice $\left(\mathrm{Palm}^{-1-}\right)$ is functional. a Images of popliteal lymph nodes of control $\mathrm{Palm}^{+/+}$mice (upper panel) and $\mathrm{Palm}^{-/-}$mice (lower panel) $8 \mathrm{~min}$ after footpad injection of Chicago Blue. b Lymphatic drainage of FITC-Dextran injected in the tail tip of Palm ${ }^{+/+}$and $\mathrm{Palm}^{-/-}$mice. Fluorescence microscopy pictures were taken 2 min after injection.

focal adhesion, reorganization of the actin cytoskeleton and the formation of membrane protrusions are impaired by the lack of paralemmin-1. A similar effect on the actin cytoskeleton has been observed in neurons where down-regulation of paralemmin-1 expression decreases the formation of filopdia [13]. Conversely, the forced expression of paralemmin-1 increases membrane protrusion formation in neuronal and also in non-neuronal cells $[12,13]$. Based on these results it is likely that paralemmin-1 acts as a linker between the plasma membrane and the cytoskeleton, necessary for the transduction of outside signals into cells. Whether paralemmin-1 plays a direct role in the recruitment of signaling molecules to the sites of action needs
B
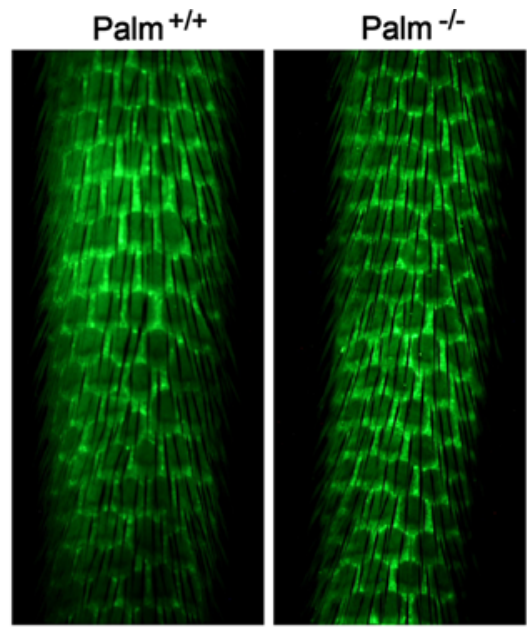

Intestine
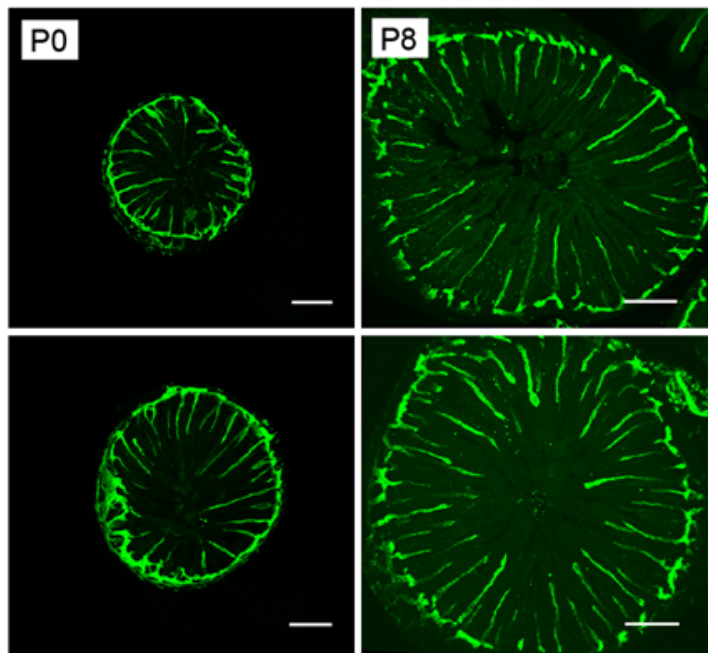

c Loss of paralemmin-1 does not disturb lymphatic vasculature development. Whole-mounts of tail (left) and intestine (right) from $\mathrm{Palm}^{+/+}$and $\mathrm{Palm}^{-1-}$ mice at the day of birth (P0) or 2 and 8 days after birth (P2, P8) were stained with antibodies against Lyve-1. Representative fluorescence microscopy pictures are shown. Scale bars $100 \mu \mathrm{m}$

further investigation. In neurons, paralemmin-1 is involved in the recruitment of AMPA-type glutamate receptors and it interacts with D3 dopamine receptors [13, 28]. Also, paralemmin-3 has been found to bind single immunoglobulin IL-1 receptor-related molecule (SIGIRR), a negative regulator of Toll-Interleukin-1 receptors, and thereby to modulate LPS-stimulated inflammatory responses [29].

Although paralemmin-1 has been found both in nonproliferating as well as in activated, proliferating LEC, its function in the development and physiology of the lymphatic system in vivo remains elusive. Our analysis of constitutive paralemmin-1 knockout $\left(\mathrm{Palm}^{-1-}\right)$ mice indicates that paralemmin-1 is not required for the 


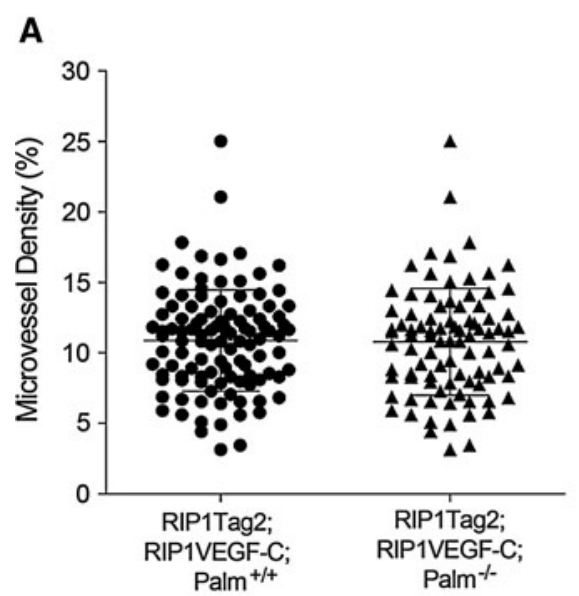

C

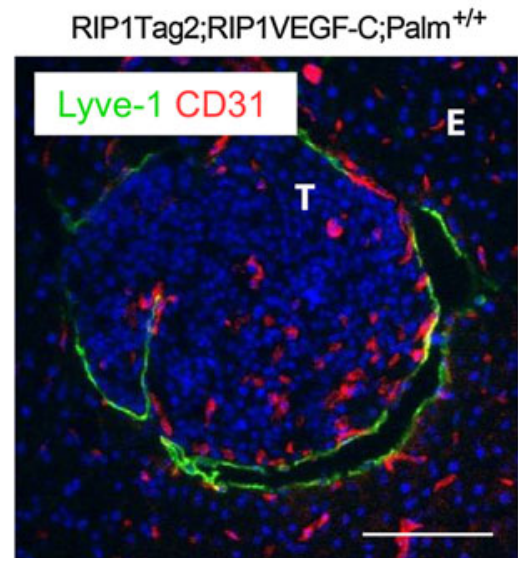

Fig. 7 Paralemmin-1 is required for pathological lymphangiogenesis. a Quantification of the intratumoral CD31-positive blood microvessel density in 12 week-old RIP1Tag2; RIP1VEGF-C; Palm ${ }^{+/+}$mice ( $\mathrm{N}=5, \mathrm{n}=109$ ) and RIP1Tag2; RIP1VEGF-C; Palm $^{-1-}$ mice $(\mathrm{N}=5, \mathrm{n}=91)$ was performed using computer-assisted image analysis. Results are displayed as percentage of CD31-stained area to total tumor area. b Quantification of the Lyve-1-positive lymphatic coverage of tumors, shown as percentage of the total tumor perimeter,

development and the physiological function of the lymphatic system. Since paralemmin-1 is expressed during the postnatal development of the lymphatic system in the intestine and the tail, the lack of "a developmental lymphatic phenotype" in $\mathrm{Palm}^{-/-}$mice may be due to compensating functions of other paralemmin family members expressed in LEC or due to paralemmin-independent homeostatic mechanisms. Preliminary results showed that LECs isolated from the skin of newborn $\mathrm{Palm}^{-1-}$ mice have increased paralemmin-2 and paralemmin-4 (also termed palmdelphin) mRNA levels compared to their levels in control LEC (Supplementary Figure 7). Structurally, paralemmin-2 and paralemmin-4 share similarities with paralemmin-1 [30], including the C-terminal CAAX lipidation motif which is essential for
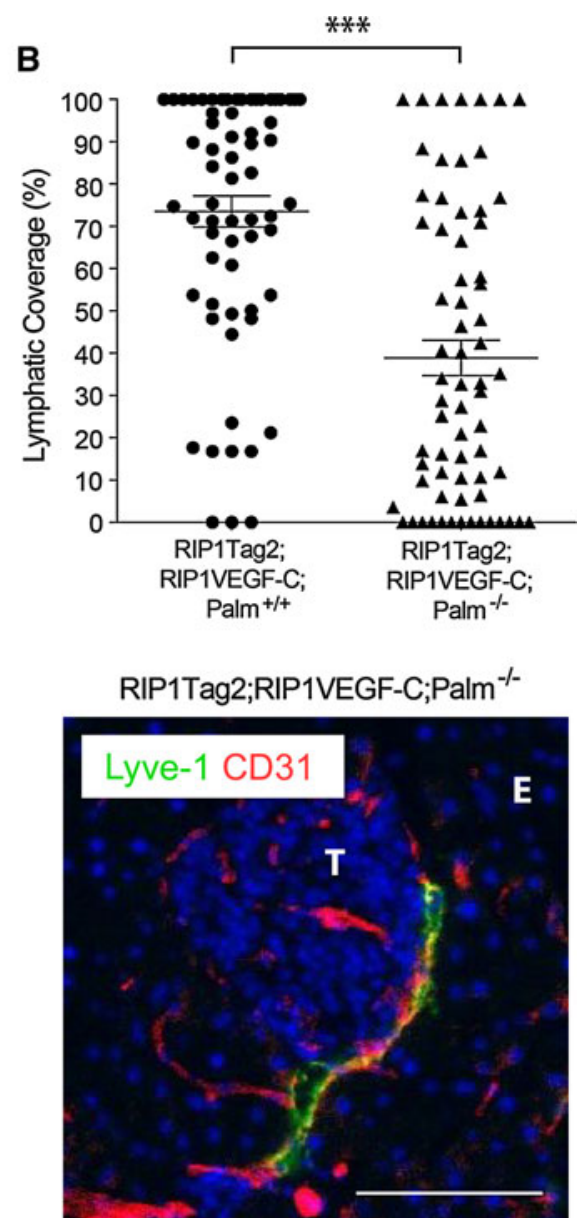

in RIP1Tag2; RIP1VEGF-C; Palm $^{+/+}$mice $(\mathrm{N}=5, \mathrm{n}=66)$ and RIP1Tag2; RIP1VEGF-C; Palm $^{-1-}$ mice $(\mathrm{N}=5, \mathrm{n}=69)$. $* * * p<0.0001$ (Student's $t$ test). $\mathrm{N}=$ number of mice, $\mathrm{n}=$ number of tumors. Standard deviations (SD) are depicted. c Representative immunofluorescence microscopy pictures of pancreatic tumor sections of RIP1Tag2; RIP1VEGF-C; Palm ${ }^{+/+}$and RIP1Tag2; RIP1VEGF-C; Palm ${ }^{-1-}$ mice stained for Lyve-1 (green) and CD31 (red). Nuclei were visualized with DAPI. Scale bars $50 \mu \mathrm{m}$

the plasma membrane localization of these proteins. Whether these similarities translate into a similar mode of action remains to be assessed. Also in the adult organism, the redundancy of several paralemmin family members or heterologous compensation may explain why lymphangiogenesis in the non-tumorigenic RIP1VEGF-C mice is independent of the presence of paralemmin- 1 . In contrast, tumor lymphangiogenesis in RIP1Tag2; RIP1VEGF-C mice, a highly acute process of lymphatic vessel formation, is clearly dependent on the presence of paralemmin-1. Together, our data indicate that paralemmin-1, with its regulation of LEC adhesion, migration and maturation and with its critical role in tumor lymphangiogenesis, is a novel marker for LEC and lymphatic vessels and a potential therapeutic target to 
interfere with tumor lymphangiogenesis and to prevent lymph node metastasis.

\section{Materials and methods}

Mouse work

All experimental procedures involving mice were approved by and performed according to the guidelines and regulations of the local committees for animal care (The Swiss Federal Veterinary Office (SFVO) and the Cantonal Veterinary Office of Basel-Stadt, permit number 1878). Constitutive paralemmin-1 knockout $\left(\mathrm{Palm}^{-/-}\right)$mice were generated by targeted deletion of exon 5 , causing a reading frame shift, by TaconicArtemis (Köln, Germany). Western blot analysis demonstrated that this is a null mutation, with protein expression in brain undetectable (detection limit $<1 \%$ of WT level). Gene construct design and KO mouse analysis will be described in more detail elsewhere. Palm $^{-1-}$ mice were crossed with single-transgenic RIP1VEGF-C or double-transgenic RIP1Tag2; RIP1VEGF-C [16] to obtain RIP1VEGF-C; $\mathrm{Palm}^{-/-}$or RIP1Tag2; RIP1VEGF-C; Palm ${ }^{-/-}$mice, respectively. All mice were kept on a C57B1/6 background.

Lymphatic drainage in the tail was analyzed by injection of $2 \mu \mathrm{l}$ of $10 \%$ FITC Dextran (2,000,000 MW, Invitrogen) dissolved in PBS into the tail tip of anaesthetized C57B1/6 control and Palm $\left(^{-1-}\right)$ mice. Five minutes after injection, pictures of the tails were taken using a fluorescent stereomicroscope (Nikon SMZ 1500, Nikon LH-M100CB-1 camera). For the examination of the lymphatic drainage to the popliteal lymph node, $10 \mu \mathrm{l}$ of a $1 \%$ Chicago Blue dye solution (Sigma-Aldrich) were injected into the hind footpad of the mice. After $8 \mathrm{~min}$, the mice were sacrificed, the popliteal lymph nodes were dissected and pictures were taken using a Nikon SMZ 1500 microscope.

To evaluate the functionality of blood vessels, $100 \mu \mathrm{l}$ of fluorescein-labeled Lycopersicon esculentum lectin (1 mg/ $\mathrm{ml}$, Vector Laboratories) in PBS were injected in the tail vein of anaesthetized mice. Five minutes after injection, mice were heart-perfused with $10 \mathrm{ml} 4 \%$ paraformaldehyde in PBS and $10 \mathrm{ml}$ PBS, and subsequently the pancreata were isolated. The phenotypical analysis of RIP1VEGF-C; Palm $^{-1-}$, RIP1Tag2; RIP1VEGF-C; Palm ${ }^{-1-}$ and their respective littermate control mice were performed between the age of 4 and 12 weeks. In tumor-bearing mice (RIP1Tag2; RIP1VEGF-C; Palm ${ }^{+/+}$and RIP1Tag2; RIP1VEGF$\mathrm{C} ; \mathrm{Palm}^{-/-}$), tumor incidence was determined per mouse by counting all macroscopically visible pancreatic tumors with a diameter above $1 \mathrm{~mm}$. The tumor volume was calculated from the measured tumor diameter assuming a spherical shape of the tumor.
Isolation of dermal lymphatic endothelial cells

Skin of newborns (age P0-P6) of control and Palm ${ }^{-1-}$ mice was isolated and then incubated in PBS supplemented with $20 \mathrm{mM}$ EDTA for $2 \mathrm{~h}$ at $37^{\circ} \mathrm{C}$. After separation of the epidermis from the dermis, skin was cut into small pieces and digested in a dispase/collagenase solution for $1 \mathrm{~h}$ at $37{ }^{\circ} \mathrm{C}$. Indigested material was removed by filtration and the single cells were washed in PBS and resuspended in HUVEC media (M199 containing $80 \mathrm{U} / \mathrm{ml}$ heparin, $40 \mathrm{mg}$ / $\mathrm{ml}$ bovine brain protein extract, $20 \%$ FBS, $4 \mathrm{mM}$ Glutamin) and plated on a gelatin-coated cell culture dish. The following day, adherent cells were removed from the cell culture plate by treatment with Accutase. For the subsequent isolation by flow-cytometry, the cells were stained with hamster anti-mouse podoplanin/anti-hamster IgG PE (Invitrogen), rat anti-mouse FITC-CD31 (BD Pharmingen) and rat anti-mouse CD45 (BD Pharmingen). Total RNA was extracted from isolated $\mathrm{CD}_{3} 1^{+}$Podoplanin ${ }^{+} \mathrm{CD} 45^{-}$ LECs using the Absolutely RNA Nanoprep Kit (Stratagene), reverse transcribed into cDNA and analyzed by semiquantitative and quantitative PCR.

\section{Gene expression profiling}

Single cell suspensions of pancreatic tumors of 12-week old RIP1Tag2; RIP1VEGF-C and islets of RIP1VEGF-C mice were prepared by dispase digestion. For subsequent isolation of tumor-derived $\mathrm{CD} 31^{+}$Podoplanin ${ }^{+}$Lyve- $1^{+}$ LEC and $\mathrm{CD} 31^{+}$BEC by flow cytometry, cells were stained with hamster anti-mouse podoplanin (Hybridoma supernatant, clone 8.1.1)/anti-hamster IgG488 (Invitrogen), rat-anti mouse PE-CD31 (BD Pharmingen) and biotinylated rabbit anti-mouse Lyve-1 (Reliatech)/Streptavidin-APC (Invitrogen). Total RNA was extracted from isolated cells using the Absolutely RNA Nanoprep Kit (Stratagene), amplified in two rounds, IVT-labeled, fragmented and hybridized to Mouse 430 A2.0 microarrays (Affymetrix).

\section{Histopathological analysis}

For histopathological analysis, the isolated organs were fixed in $4 \%$ paraformaldehyde (Sigma) for $2 \mathrm{~h}$ at $4{ }^{\circ} \mathrm{C}$, then incubated over night in $30 \%$ sucrose in PBS and finally embedded in OCT (Tissue Tek). Immunostaining was performed on $7 \mu \mathrm{m}$ cryosections. After cutting, tissue sections were placed on slides, washed with PBS and then blocked for $60 \mathrm{~min}$ at RT with $5 \%$ goat serum in PBS. Sections were incubated for $60 \mathrm{~min}$ with primary antibodies diluted in blocking buffer, washed with PBS and incubated with secondary antibodies diluted in blocking buffer. After $30 \mathrm{~min}$, sections were washed with PBS, 
nuclei were counterstained with 6-diamidino-2-phenylindole (Sigma) and slides were mounted.

The following antibodies were used: rabbit anti-mouse paralemmin-1 [24], rabbit anti-mouse Prox-1 (obtained from K. Alitalo, University of Helsinki, Finland), hamster anti-mouse podoplanin (Hybridoma supernatant, clone 8.1.1), rabbit anti-mouse Lyve-1 (Reliatech), rat antimouse CD31 (BD Pharmingen ${ }^{\mathrm{TM}}$ ), guinae pig anti-mouse insulin (Dako), rabbit anti-human paxillin (Abcam) and AlexaFluor 568 phalloidin (Invitrogen). Secondary antibodies were conjugated either with Alexa Fluor 488 or 568 (Invitrogen). Viewing of stained sections and picture acquisition was done on a Leica DMI 4000 fluorescence microscope or a Zeiss LSM 510 Meta laser scanning confocal microscope. Microvessel density and lymphatic coverage of islets and tumors were quantified using ImageJ software (Rasband, W.S., Image J, U. S. National Institutes of Health, Bethesda, Maryland, USA, http://rsb.info.nih. gov/ij/, 1997-2007) and are displayed as \% of CD31positive stained area of total islet or tumor area and of stained Lyve-1-postive perimeter to total islet or tumor perimeter, respectively.

\section{Whole mount staining}

Whole-mount staining was performed with tail and intestine of newborn as well as with ear and diaphragm of adult C57B1/6 control and Palm ${ }^{-1-}$ mice. Organs were isolated, cut into small pieces and fixed in $4 \%$ paraformaldehyde in PBS for $4 \mathrm{~h}$ at RT. After washing, tissue were blocked in $5 \%$ goat serum, $0.2 \%$ BSA, $0.3 \%$ Triton $\mathrm{X}-100$ in PBS $\mathrm{O} / \mathrm{N}$ at $4{ }^{\circ} \mathrm{C}$, followed by over night incubation with rabbit anti-mouse Lyve-1 (Reliatech) antibody diluted in blocking solution. After 5 washes with $0.3 \%$ Triton X-100, PBS for 20 min at RT, tissue were incubated with anti-rabbit fluorophore-conjugated antibody diluted in blocking solution. After $5 \mathrm{~h}$ incubation, tissue were washed three times with $0.3 \%$ Triton X-100, PBS for $15 \mathrm{~min}$ at RT, then fixed for 5 min with $4 \%$ paraformaldehyde in PBS, washed with PBS three times for $5 \mathrm{~min}$ at RT and mounted with Moviol. Picture stacks of the stained organs were acquired on a Zeiss, LSM 510 Meta confocal microscope and converted into 3D images using Imaris Software (Bitplane).

\section{Cell culture}

The mouse lymphatic endothelial cell lines SV-LEC and MELC were obtained from J.S. Alexander (Louisiana State University, USA) and A. Vecchi (Mario Negri Institute, Milan, Italy), respectively. Both cell lines were cultured as previously described $[17,18]$. For the generation of transient paralemmin-1 knockdown cells, cells were transfected with siControl, siPalm (1) or siPalm (2) (Sigma) with a final concentration of $10 \mathrm{nM}$. Transfection of SV-LEC was performed with Lipofectamine ${ }^{\mathrm{TM}}$ RNAiMAX (Invitrogen) reagents following the manufacturer's instructions. Paralemmin-1 expression was analyzed by quantitative RT-PCR and immunoblotting. Stable paralemmin-1 knockdown MELC were generated using a lentiviral transduction system. Lentiviral particles with the expression vectors pLenti-shPalm (Sigma) were generated in HEK293T cells. Cells were transfected with the expression vector using FuGENE $^{\circledR}$ HD Transfection Reagent (Roche) according to the manufacturer's protocol. Sixty hours after transfection, the supernatant of the transfected HEK293T cells containing the viral particles was filtered through a $0.45 \mu \mathrm{m}$ filter (Millipore), diluted 1:1 with normal growth medium and added to the MELC for $24 \mathrm{~h}$. The infection was repeated once and infected cells were selected with $5 \mathrm{ng} / \mu \mathrm{l}$ puromycin (Sigma) for 1 week. Paralemmin-1 expression was analyzed by quantitative RT-PCR and immunoblotting and stable shPalm MELC and control cells were used for further functional analysis. For immunofluorescence stainings, cells were seeded on glass slides or cell culture dishes and then fixed with $4 \%$ paraformaldehyde for $10 \mathrm{~min}$ at $37^{\circ} \mathrm{C}$. Subsequent stainings were performed as described in the section 'Histopathological analysis'.

\section{Semiquantitative and quantitative RT-PCR}

Total RNA was extracted from cells or from tissues using Trizol reagent (Sigma), and reverse-transcribed in cDNA with random hexamer primers using ImProm-II ${ }^{\mathrm{TM}}$ Reverse Transcriptase (Promega). RNA from flow cytometry-sorted cells was extracted with the Absolutely RNA Nanoprep Kit (Stratagene) and amplified prior PCR analysis using the WT-Ovation Pico RNA amplification (NuGEN Technologies, Inc.). mRNA transcript levels were quantified on a StepOnePlus Real Time PCR System (Applied Biosystems) with SYBR Green Master mix (Eurogentec). Transcript expression levels were normalized against the housekeeping genes mouse guanosine disphosphate dissociation inhibitor 2 (mGDI2) or mouse TATA-box-binding protein (mTbP) and were displayed as $\triangle \mathrm{CT}$ values or fold changes. Primers for semi-quantitative PCR: mPalm1: fwd: $5^{\prime}$-AAA GAGAATCGCACGTCCAC-3' , rev: 5'-TCGCTCAGTGT GACCTCATC-3'; mPalm2: fwd: $5^{\prime}$-CTGCCTTCTAGGA

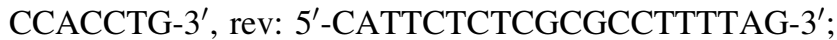
mPalm3: fwd: $5^{\prime}$-ATTCGCAACCTGGAAGACAG- ${ }^{\prime}$, rev: 5'-GGAAGTTCGCTTGTCCACAT-3'; mPalm4 (Palmd): fwd: $5^{\prime}$-TTGGACTTCCTTCAGCGTCT-3' ${ }^{\prime}$, rev: $5^{\prime}$-TGCTG GTCTTGCTGATTTTG-3'; mActin: fwd: $5^{\prime}$-ACACTGT GCCCATCTACGAGG-3', rev: 5-CATGCATGCCACAGG ATTCC-3'. 
Primers for quantitative PCR: mPalm1: fwd: $5^{\prime}-\mathrm{CGACG}$ AGGACATGAGGAAAC-3', rev: 5'-TCTCCAAACTCCA GAACATCG-3'; mPalm2: fwd: 5'-GAAGATGAATTCAA AGTCAAGC-3', rev: 5'-TTTCGAGCGCTTGTATTTCC3'; mPalm3: fwd: 5'-ACACAGACCTGCTGGTAGGC-3', rev: 5'-AGTTCGCTTGTCCACATCAGT-3'; mPalm4: fwd: 5'-AAATTGAAACACCAACATCTGAAG-3', rev: 5'-CTTTTCCACTGCCGATTCC-3'; mGDI2: fwd: 5'-CC CTATCAAGAACACCAACGA-3', rev: 5'-TGCAAAGG AGATCATGCAAA-3'; mTbp: fwd: 5'-CTGGAATTGT ACCGCAGCTT-3', rev: 5'-TCCTGTGCACACCATTTT TC-3'; mCD31: fwd: 5'-GGAGTCAGAACCCATCAGG A-3', rev: 5'-TACTGG GCTTCGAGAGCATT-3'; mProx1: fwd: 5'-AAGTGGTTCAGCAATTTCCG-3', rev: 5'-TG ACCTTGTAAATGGCCTTC-3'; mLyve-1: fwd: $5^{\prime}$-TTCC TCGCCTCTATTTGGAC-3', rev: 5'-ACGGGGTAAAAT GTGGTAAC-3'; mNG2: fwd: 5'-TGATTCCTTCTCCCT GGATG-3'.

\section{Immunoblotting}

Cells and tissue were lysed in ice-cooled RIPA-plus buffer [50 mM Tris- $\mathrm{HCl} \mathrm{pH} 8,150 \mathrm{mM} \mathrm{NaCl}, 2 \mathrm{mM} \mathrm{MgCl}_{2}$, $2 \mathrm{mM} \mathrm{CaCl}_{2}, 0.5 \%$ NaDoc, $10 \%$ glycerol, $1 \% \mathrm{NP} 40$, $0.1 \% \mathrm{SDS}, 1 \mathrm{mM} \mathrm{NaF}, 2 \mathrm{mM} \mathrm{NaVO}, 1 \mathrm{mM}$ DTT, and protease inhibitor cocktail (Sigma)]. Cleared protein lysates were separated by SDS-PAGE, transferred on PDVF membranes and stained for paralemmin-1 and tubulin (Sigma).

\section{Migration assay}

$25 \times 10^{3}$ of control and paralemmin-1 knockdown cells resuspended in $100 \mu \mathrm{l}$ DMEM, $0.5 \%$ FBS were plated in the transwell insert (pore size $8 \mu \mathrm{m}$, Falcon ${ }^{\circledR}$, Becton-Dickinson) which was placed afterwards in a 24-well plate (Falcon $^{\circledR}$, Becton-Dickinson) filled with $500 \mu$ l complete growth medium. Cells were allowed to migrate for $6 \mathrm{~h}$ at $37{ }^{\circ} \mathrm{C}$. Subsequently cells were fixed with $4 \%$ paraformaldehyde (Sigma), nuclei were stained with DAPI $(5 \mu \mathrm{g} / \mathrm{ml}$, Sigma) and non-migrated cells were removed with a cotton swab. Pictures were taken with a fluorescence microscope (Leica DMI 4000) at $10 \times$ magnification and the total number of cells was counted in 5 fields by ImageJ software (Rasband, W.S., ImageJ, U. S. National Institutes of Health, Bethesda, Maryland, USA, http://rsb.info.nih.gov/ij/, 1997-2012). Each experiment was done in triplicates, and one representative experiment is shown.

\section{Cord formation assay}

The ability of endothelial cells to form cord-like structures on Matrigel (growth factor reduced, high concentration,
BD Biosciences) was studied using $\mu$-slides (ibidi). $10 \mu \mathrm{l}$ Matrigel was added per well, and after solidification of Matrigel by incubation at $37{ }^{\circ} \mathrm{C}$ for $20 \mathrm{~min}, 12.5 \times 10^{3}$ control or paralemmin-1 knock-down cells resuspended in $50 \mu \mathrm{l}$ complete growth medium were layered on top. After $1 \mathrm{~h}$ and $2 \mathrm{~h}$ incubation at $37^{\circ} \mathrm{C}$, pictures were taken by a light microscope (Leica DMIL) at $10 \times$ magnification. The cells outside cord-like structures were counted manually and related to the total seeded cell number. Each experiment was done in triplicates, and one representative experiment is shown.

\section{Live cell imaging}

The adhesion and spreading behavior of LEC upon loss of paralemmin-1 was studied in a Ludin chamber (Life Imaging Services) by reflection interference contrast microscopy (RICM). $75 \times 10^{3}$ SV-LEC washed once with PBS and resuspended in $1 \mathrm{ml}$ DMEM containing $20 \mathrm{nM}$ HEPES buffer (Sigma) were seeded into a Ludin chamber on $18 \mathrm{~mm}$ glass coverslips (Assistant), which have been pre-coated with $0.01 \%$ poly-L-lysine solution (Sigma) for $1 \mathrm{~h}$ at $37^{\circ} \mathrm{C}$. Cell spreading was monitored by taking RICM pictures every $5 \mathrm{~s}$ with a live-cell imaging microscope (Axiovert $35 \mathrm{M}$, ZEISS) using red fluorescent light $(\lambda=565 \mathrm{~nm})$, a $40 \times$ magnification and a high resolution CCD camera (CoolSNAP EZ, Photometrics ${ }^{\circledR}$ ). Cell spreading was quantified using ImageJ software and adhesion areas were normalized to $100 \%$. For fibronectin lines, the $18 \mathrm{~mm}$ coverslips were coated with PLL-PEG $(0.5 \mathrm{mg} / \mathrm{ml}$, SuSoS AG) for $30 \mathrm{~min}$ at RT, washed one with $\mathrm{ddH}_{2} \mathrm{O}$ followed by a second washing step with $100 \%$ EtOH (Reuss Chemie). Polydimethylsiloxan (PDMS) line patterns (10 $\mu \mathrm{m}$ lines, $50 \mu \mathrm{m}$ gaps) were cut in reasonable size, cleaned with tape, placed on the coated coverslips and treated for 2 min with plasma. Afterwards, line patterns were removed, coated with fibronectin $(5 \mu \mathrm{g} / \mu \mathrm{l}, 30 \mathrm{~min}$, RT) washed with PBS and placed into a Ludin chamber. $10 \times 10^{3} \mathrm{SV}$-LEC resuspended in $1 \mathrm{ml}$ DMEM, $1 \mathrm{mM}$ Gln, $10 \%$ FCS, 20 nM HEPES buffer were seeded into the Ludin chamber and pictures were taken every $5 \mathrm{~s}$ using a live-cell imaging microscope (Axiovert $35 \mathrm{M}$, Zeiss) at $40 \times$ magnification with a high resolution CCD camera (CoolSNAP EZ, Photometrics ${ }^{\circledR}$ ).

Acknowledgments We are grateful to H. Antoniadis, R. Jost, I. Galm and P. Schmidt for technical support. The authors thank H. Kohler (Friedrich Miescher Institute, Basel) and P. Demougin (University of Basel) for expertise in cell sorting and gene expression profiling, K. Martin (University of Basel) for help with the cell culture experiments on fibronectin lines, P. Lorentz (University of Basel) for expert microscopy analysis, J.S. Alexander (Louisiana State University, USA) and A. Vecchi (Mario Negri Institute, Milan, Italy) for cell lines, and K. Alitalo (Biomedicum Helsinki, Finland) for antibodies. This work was supported by the Swiss Cancer League, the Swiss 
National Science Foundation NCCR 'Molecular Oncology', and by Bayer-Schering Pharma AG.

Conflict of interest The authors declare no competing financial interests.

\section{References}

1. Alitalo A, Detmar M (2012) Interaction of tumor cells and lymphatic vessels in cancer progression. Oncogene 31:4499-4508

2. Albrecht I, Christofori G (2011) Molecular mechanisms of lymphangiogenesis in development and cancer. Int $\mathrm{J}$ Dev Biol 55:483-494

3. Duong T, Koopman P, Francois M (2012) Tumor lymphangiogenesis as a potential therapeutic target. J Oncol 2012:204946

4. Hirakawa S (2011) Regulation of pathological lymphangiogenesis requires factors distinct from those governing physiological lymphangiogenesis. J Dermatol Sci 61:85-93

5. Stacker SA, Caesar C, Baldwin ME, Thornton GE, Williams RA, Prevo R et al (2001) VEGF-D promotes the metastatic spread of tumor cells via the lymphatics. Nat Med 7:186-191

6. Cao R, Bjorndahl MA, Religa P, Clasper S, Garvin S, Galter D et al (2004) PDGF-BB induces intratumoral lymphangiogenesis and promotes lymphatic metastasis. Cancer Cell 6:333-345

7. Baluk P, Yao LC, Feng J, Romano T, Jung SS, Schreiter JL et al (2009) TNF-alpha drives remodeling of blood vessels and lymphatics in sustained airway inflammation in mice. J Clin Invest 119:2954-2964

8. Maruyama K, Ii M, Cursiefen C, Jackson DG, Keino H, Tomita $M$ et al (2005) Inflammation-induced lymphangiogenesis in the cornea arises from CD11b-positive macrophages. J Clin Invest 115:2363-2372

9. Kerjaschki D, Huttary N, Raab I, Regele H, Bojarski-Nagy K, Bartel $G$ et al (2006) Lymphatic endothelial progenitor cells contribute to de novo lymphangiogenesis in human renal transplants. Nat Med 12:230-234

10. Zumsteg A, Baeriswyl V, Imaizumi N, Schwendener R, Ruegg C, Christofori G (2009) Myeloid cells contribute to tumor lymphangiogenesis. PLoS ONE 4:e7067

11. Hultqvist G, Ocampo Daza D, Larhammar D, Kilimann MW (2012) Evolution of the vertebrate paralemmin gene family: ancient origin of gene duplicates suggests distinct functions. PLoS ONE 7:e41850

12. Kutzleb C, Sanders G, Yamamoto R, Wang X, Lichte B, Petrasch-Parwez E et al (1998) Paralemmin, a prenyl-palmitoylanchored phosphoprotein abundant in neurons and implicated in plasma membrane dynamics and cell process formation. J Cell Biol 143:795-813

13. Arstikaitis P, Gauthier-Campbell C, Carolina Gutierrez Herrera R, Huang K, Levinson JN, Murphy TH et al (2008) Paralemmin1 , a modulator of filopodia induction is required for spine maturation. Mol Biol Cell 19:2026-2038

14. Gauthier-Campbell C, Bredt DS, Murphy TH, El-Husseini A-D (2004) Regulation of dendritic branching and filopodia formation in hippocampal neurons by specific acylated protein motifs. Mol Biol Cell 15:2205-2217
15. Hanahan D (1985) Heritable formation of pancreatic beta-cell tumours in transgenic mice expressing recombinant insulin/simian virus 40 oncogenes. Nature 315:115-122

16. Mandriota SJ, Jussila L, Jeltsch M, Compagni A, Baetens D, Prevo R et al (2001) Vascular endothelial growth factor-Cmediated lymphangiogenesis promotes tumour metastasis. EMBO J 20:672-682

17. Ando T, Jordan P, Joh T, Wang Y, Jennings $\mathrm{MH}$, Houghton J et al (2005) Isolation and characterization of a novel mouse lymphatic endothelial cell line: SV-LEC. Lymphat Res Biol 3:105-115

18. Sironi M, Conti A, Bernasconi S, Fra AM, Pasqualini F, Nebuloni $M$ et al (2006) Generation and characterization of a mouse lymphatic endothelial cell line. Cell Tissue Res 325:91-100

19. Giannone G, Dubin-Thaler BJ, Dobereiner HG, Kieffer N, Bresnick AR, Sheetz MP (2004) Periodic lamellipodial contractions correlate with rearward actin waves. Cell 116:431-443

20. DiMilla PA, Stone JA, Quinn JA, Albelda SM, Lauffenburger DA (1993) Maximal migration of human smooth muscle cells on fibronectin and type IV collagen occurs at an intermediate attachment strength. J Cell Biol 122:729-737

21. Palecek SP, Loftus JC, Ginsberg MH, Lauffenburger DA, Horwitz AF (1997) Integrin-ligand binding properties govern cell migration speed through cell-substratum adhesiveness. Nature 385:537-540

22. Petrie RJ, Doyle AD, Yamada KM (2009) Random versus directionally persistent cell migration. Nat Rev Mol Cell Biol 10:538-549

23. Xu Y, Yuan L, Mak J, Pardanaud L, Caunt M, Kasman I et al (2010) Neuropilin-2 mediates VEGF-C-induced lymphatic sprouting together with VEGFR3. J Cell Biol 188:115-130

24. Kutzleb C, Petrasch-Parwez E, Kilimann MW (2007) Cellular and subcellular localization of paralemmin-1, a protein involved in cell shape control, in the rat brain, adrenal gland and kidney. Histochem Cell Biol 127:13-30

25. Turk CM, Fagan-Solis KD, Williams KE, Gozgit JM, SmithSchneider S, Marconi SA et al (2012) Paralemmin-1 is overexpressed in estrogen-receptor positive breast cancers. Cancer Cell Int 12:17

26. Fackler OT, Grosse R (2008) Cell motility through plasma membrane blebbing. J Cell Biol 181:879-884

27. Zaidel-Bar R, Cohen M, Addadi L, Geiger B (2004) Hierarchical assembly of cell-matrix adhesion complexes. Biochem Soc Trans 32:416-420

28. Basile M, Lin R, Kabbani N, Karpa K, Kilimann M, Simpson I et al (2006) Paralemmin interacts with D3 dopamine receptors: implications for membrane localization and cAMP signaling. Arch Biochem Biophys 446:60-68

29. Chen X, Wu X, Zhao Y, Wang G, Feng J, Li Q et al (2011) A novel binding protein of single immunoglobulin IL-1 receptorrelated molecule: paralemmin-3. Biochem Biophys Res Commun 404:1029-1033

30. Hultqvist G, Ocampo Daza D, Larhammar D, Kilimann MW (2012) Evolution of the vertebrate paralemmin gene family: ancient origin of gene duplicates suggests distinct functions. PLoS ONE 7:e41850 